\title{
REFLEXÕES SOBRE O ACESSO A MUSEUS E INSTITUIÇÕES CULTURAIS
}

Paula Hilst Selli

\section{RESUMO}

Este artigo traz um recorte da pesquisa de mestrado "Crianças, museus e formação de público em São Paulo" concluída na Universidade Estadual Paulista "Júlio de Mesquita Filho" - UNESP em 2011. O texto traz algumas reflexões sobre a questão do acesso a museus e instituições culturais a partir das falas das crianças participantes da pesquisa em diálogo com diversos autores e pesquisas que trataram sobre o tema como Bourdieu, Falk, Almeida, Mantecon, Botelho e Darras, entre outros. Trata-se de pensar o acesso aos museus não apenas do ponto de vista material e numérico, mas como possibilidade e escolha.

Palavras-chave: museu, acesso, público

\section{ABSTRACT}

This article is a part of master's research, "Crianças, museus e formação de público em São Paulo" made at UNESP in 2011. In the text we talk about access to museums and cultural institutions. We started with the speech of children and then we based some authors to reflect on how people come or not come to museums. More than think only in material issue, this paper proposes think access as choice and potentiality.

Keywords: museum, access, public

\section{Criança 1 - "É assim, o museu, assim, quando você quando era criança não podia ver." Paula - "Por que quando era criança não podia ver?" Criança 1 - "Porque a gente ainda não conhecia nada".}

Em minha pesquisa de mestrado ${ }^{1}$ concluída na Universidade Estadual Paulista "Júlio de Mesquita Filho" (UNESP) no ano de 2011 conversei com 95 crianças com cerca de 9 anos de idade provenientes de 4 escolas do município de São Paulo, entre públicas e privadas. As conversas giraram em torno do assunto "museu" e a partir delas pude descobrir e refletir sobre vários pontos importantes para a relação criança-museu na cidade de São Paulo.

\footnotetext{
${ }^{1}$ SELLI (2011) ${ }^{1}$ SELLI - Licenciada em Educação Artística com habilitação em Artes Plásticas pela ECA-USP, mestre em Artes pelo Instituto de Artes da UNESP. Educadora do Museu Lasar Segall - IBRAM/MinC.
} 
Um ponto que me interessava desde o princípio e que se tornou mais forte com as falas das crianças foi a questão do acesso a essas instituições. Assim, pude buscar nas experiências das crianças aspectos para discussão sobre acesso e formação de público de museus e instituições culturais na cidade de São Paulo, e percebi que a questão causava grande interesse e polêmica entre elas, mostrando-nos uma necessidade de falar mais sobre o assunto, de refletir, de buscar fundamentos.

Este artigo traz uma parte dessa reflexão, trata-se de um recorte da pesquisa realizada em São Paulo, com enfoque no debate sobre o acesso aos espaços e bens culturais. Trarei, de início, um resumo dos resultados obtidos com as crianças, suas falas, preocupações e críticas para dar ao leitor uma maior proximidade com o material de pesquisa motivador desta discussão. Em seguida trarei as falas de alguns autores que pensaram e pesquisaram sobre o acesso a museus e instituições culturais, que junto às falas das próprias crianças são os fios para a tecedura de mais uma discussão sobre o acesso, tema conhecido, mas ainda carente de exploração.

\section{A voz das crianças}

"Eu acho que tem que pagar [para entrar nos museus], mas tem uns que não podem pagar, mas eles entram a gente de graça." (criança 2)

É preciso primeiro estabelecer rapidamente quem são essas crianças que participaram da pesquisa e qual a relação que elas têm com o museu. Todas as crianças estavam na época de realização da pesquisa na terceira série (atual quarto ano) do ensino fundamental e, de acordo com os resultados da pesquisa, a grande maioria já havia visitado um museu, embora esse não pudesse ser considerado um hábito frequente para a maioria delas.

As crianças também citaram a família e a escola como principais responsáveis por levá-las aos museus, com relativo destaque para a posição da família. Disseram que gostavam de ir ao museu e o associaram principalmente à apreciação e à aprendizagem. Em uma das escolas houve uma associação grande entre museu e lazer.

Durante a pesquisa de campo as crianças responderam, através de um jogo, a 11 perguntas sobre os museus. A partir dessas respostas fazíamos uma roda de conversas onde as principais questões eram debatidas e aprofundadas. Entre todas as perguntas feitas às crianças, nenhuma provocou tanta polêmica e discussão como a pergunta sobre se todas as pessoas podem ir aos museus. 
Podemos registrar dois momentos: primeiro, a ocasião da resposta individual durante o jogo das perguntas que gerou um resultado, depois, as respostas nas rodas de conversa. Algumas crianças mudaram sua opinião quando ouviram os colegas, o que é natural, e elas mesmas puderam explicar. Outras a mantiveram e brigaram por ela. De qualquer forma, antes e após a conversa, as crianças continuaram divididas quanto a se todos podem ou não ir aos museus.

Nas respostas ao jogo de perguntas, 69\% das crianças achou que sim, todos podem ir a museus. O que percebemos é que, embora a maioria tenha considerado que todos podem ir aos museus, o número que percebe problemas no acesso é bem significativo também.

Entre as crianças que acreditam que todos podem ir ao museu 32,3\% (o grupo mais significativo) recorreu à questão dos direitos humanos e dos bens públicos para explicar suas respostas. Quanto aos motivos apresentados pelas crianças que acham que nem todos podem ir ao museu, ou que apresentaram a resposta talvez, se destaca principalmente a questão socioeconômica, com 57,14\% das crianças desse grupo. Outros motivos foram apresentados com pouco destaque como idade para frequentar museus, responsabilidades e interesses pessoais, porém algumas dessas categorias ganharam ênfase e outras surgiram durante as rodas de conversa.

Nas rodas de conversa o grande embate entre a característica pública do museu e a questão socioeconômica foi mantido, sendo que a característica pública do museu continua a ser destacado com muita ênfase pelas crianças que acreditam que todos podem ir aos museus. Por outro lado as crianças apontaram também com bastante destaque perfis que consideram não aceitos, ou não adequados ao espaço do museu. Em duas escolas aparece de forma clara a figura do "ladrão" e, em uma delas, junto a uma terceira, aparece as crianças pequenas, que, segundo as crianças participantes, não deveriam ir ao museu.

"Eu acho que as crianças pequenas não podem ir ao museu porque elas não vão se divertir muito porque não tem coisas que são pra idade delas e não podem fazer barulho que atrapalha as pessoas para ver as coisas e elas podem quebrar as coisas." (criança 3) Algumas crianças falaram sobre adultos que não podem ir aos museus porque trabalham, e falaram novamente muitas vezes dos preços dos ingressos. Em uma das escolas algumas crianças levantaram, porém, o fato de que se alguém não pode pagar pelos ingressos dos museus, elas podem visitá-los com a ajuda de terceiros (que permitem uma entrada gratuita 
para quem não tem dinheiro, que são pessoas boas e/ou que tem responsabilidade de "dar para os pobres").

O mais interessante é que o assunto do acesso foi relevante para todas as turmas pesquisadas e causou polêmica entre as crianças. Através de suas falas pude perceber que, embora a maioria dessas crianças acredite que todos possam ir aos museus, conseguem enxergar também fatores que dificultam com que esse acesso se realize. Falam-nos de preconceitos e distanciamentos, de códigos culturais e problemas sociais, de direitos e de realidade.

\section{Reflexões sobre o acesso - o público atual dos museus}

"Por que tem algumas pessoas que moram na rua querem visitar os museus não podem porque não tem dinheiro." (criança 4)

As crianças percebem os aspectos que cercam esta questão: aspectos socioeconômicos, outros referentes a preconceitos e perfis de comportamento não aceitos socialmente, a faixa etária dos visitantes e a condição pública do museu foram abordados por elas.

Mas como essas percepções das crianças conversam com pesquisas de público diversas? Como as pesquisas confirmam, ou não, as percepções dessas crianças? E como essas percepções podem nos alertar para como o museu está recebendo seu público infantil?

A pesquisadora mexicana Ana Rosas Mantecón esclarece que:

O papel de público na modernidade é produto do surgimento de uma oferta cultural que convoca à participação de outros e que se faz pública: a princípio (e só a princípio) qualquer pessoa que deseja assistir e possa pagar por isso (no caso do acesso ter um custo) tem a liberdade de fazê-lo, sem importar seu pertencimento a alguma instituição, posição ou grupo. (...) Não foi assim até que os bens culturais se fizessem públicos, isto é, que começassem a ser produzidos para o mercado e mediados por ele, que na sua qualidade de mercadorias se tornassem universalmente acessíveis. (MANTECON, 2009, p. 178-180)

Mantecon (2009) problematiza o acesso universal. De fato, pesquisas de público realizadas recentemente contribuem para que percebamos a distância deste ideal de acesso. Em uma 
pesquisa realizada pelo Observatório de Museus em 2006 e 2007 em treze museus² do estado de São Paulo (a maioria deles localizado na capital) foi constatado, mais uma vez, que o público de museus é formado principalmente por adultos jovens (até 40 anos), de escolaridade muito acima da média da população em geral. A renda é prioritariamente média alta e alta, com representação significativa da faixa de renda inferior, representada pelos estudantes que exercem atividades de estagiários e bolsistas, mas com pouquíssima participação de pessoas de renda média inferior ${ }^{3}$ (OBSERVATÓRIO DE MUSEUS, 2008).

Embora encontremos diferenças ao analisarmos os resultados por instituição, principalmente em relação à faixa etária (alguns museus apresentam público prioritariamente mais velho, como o Museu da Casa Brasileira e a Bolsa do Café em Santos, enquanto outros principalmente estudantes, como o Paço das Artes e o MAM de acordo com a vocação de cada instituição), o alto grau de renda e escolaridade encontra poucas exceções. O Museu Índia Vanuíre e o MAE são aqueles que apresentaram uma parcela maior de visitantes de baixa renda em relação aos demais.

Outras pesquisas da mesma década reforçam esses dados. A Pinacoteca do Estado, por exemplo, realizou pesquisas de perfil de público em 2002 e 2008 (PINACOTECA, 2002 E PINACOTECA, 2008). Em 2002 foi registrado que a maioria dos visitantes possuía ou cursava ensino superior, possuia renda média alta ou alta e era predominantemente jovem. Essa pesquisa colaborou para que a Pinacoteca pensasse suas ações educativas, entendendo quem visitava e buscando quem não visitava o museu. Ainda assim, em 2007, outra pesquisa se fez necessária e a Pinacoteca entrevistou pessoas nas ruas próximas à instituição, para saber se elas a conheciam e se a frequentavam, com resultados negativos ${ }^{4}$. Em 2008, outra pesquisa de perfil de público foi feita, e a concentração de pessoas com superior completo e a grande participação dos estudantes reafirmou os resultados encontrados em 2002.

\footnotetext{
${ }^{2}$ A pesquisa foi realizada nos seguintes museus: Pinacoteca do Estado, Estação Pinacoteca, Museu da Língua Portuguesa, Museu da Casa Brasileira, Memorial do Imigrante, Museu da Imagem e do Som, Paço das Artes, Museu Histórico Pedagógico Índia Vanuíre (Tupã), Museu Casa de Portinari (Brodósqui), Museu do Café da Bolsa de Santos (Santos), Museu de Arte de São Paulo, Museu de Arqueologia e Etnologia da USP e Museu Lasar Segall.

${ }^{3}$ A faixa inferior correspondia a até $\mathrm{R} \$ 500,00$, a faixa média inferior correspondia à rendas de $\mathrm{R} \$ 500,00$ a $R \$ 2000,00$, as médias superiores iam de $R \$ 2000,00$ a $R \$ 4000,00$ e as superiores eram as maiores de $\mathrm{R} \$ 4000,00$. Dados de 2006 e 2007.

${ }^{4}$ Percebeu-se que a grande maioria da população do entorno, mesmo passando pela região com freqüência, nunca havia entrado na Pinacoteca. Esta pesquisa também foi importante por revelar os motivos que levam as pessoas do entorno a não se aproximar do museu, evidenciando questões referentes à percepção do museu e dos perfis tidos como aceitos para tais instituições. (PINACOTECA, 2007)
} 
Interessada em conhecer os perfis de público associados às diferentes tipologias de museus, Adriana Mortara de Almeida (2004) realiza no ano de 2003 uma pesquisa em três grandes museus de São Paulo: um de arte (a Pinacoteca), um de ciências (o Museu de Zoologia da USP) e um histórico (o Museu Paulista da USP). No perfil encontrado o público com alta escolaridade e renda permanece como maioria. O Museu Paulista apresentou ainda uma parcela significativa de visitantes com escolaridade média. O que é possível perceber a partir da pesquisa de Almeida e da relação com as outras pesquisas apresentadas pela autora é que o Museu Paulista mantém o mesmo público de alta escolaridade que os outros museus, mas além destes recebe um grande contingente extra, que não chega aos museus de outras tipologias e apelos.

Almeida traz também pesquisas internacionais ${ }^{5}$ para mostrar que essa questão da influência da renda e escolaridade confirma o que já fora encontrado em outros países.

Todas as pesquisas de perfil de público de museus evidenciam a alta escolaridade como característica dos visitantes. Assim, todos os tipos de museus recebem visitas de pessoas com nível superior (graduação e pósgraduação) e só alguns atraem o público menos escolarizado, geralmente zoológicos, centros de ciências e parques. Fenômeno análogo se dá em relação à renda e ao padrão socioeconômico. (ALMEIDA, 2004, P. 291)

Todas essas pesquisas indicam também que a maioria das pessoas visita os museus acompanhada, sendo que, pela pesquisa de Almeida (2004) percebe-se que o Museu de Zoologia e o Museu Paulista têm um apelo maior para famílias com crianças do que a Pinacoteca. Ainda assim, a motivação social continua a representar elevados percentuais em todas as tipologias de museus:

No Museu de Zoologia, 50\% dos acompanhantes estão entre 0 e 15 anos de idade, indicando uma clara preferência dos adultos por trazer o público infanto-juvenil a esse espaço. Já no Museu Paulista essa faixa, também a mais frequente, representa $29 \%$ dos acompanhantes. Na Pinacoteca, ela só corresponde a $13 \%$ dos acompanhantes, a quarta mais frequente. Esses resultados parecem confirmar que o museu de ciência atrai mais público infanto-juvenil do que o museu de arte. Já o Museu Paulista apresenta um perfil intermediário, tendo frequência de público infanto-juvenil alta, porém menor que o Museu de Zoologia (...). (ALMEIDA, 2004, p. 285)

\footnotetext{
${ }^{5}$ SCHUSTER, 1992; LINTON et al., 1992; LEHALLE; MIRONER, 1993; CIMET et al., 1987; CLARK et al., 1985; DIGBY, 1973; DOERING; BICKFORD, 1997 apud ALMEIDA, 2004
} 
As diferenças de perfis de público encontradas por Almeida nas três tipologias de museus também já haviam sido encontradas nos museus do Smithsonian Institution (DOERING e BICKFORD, 1997 apud ALMEIDA, 2005), onde os museus ligados à ciência recebem mais famílias com crianças que os demais.

De acordo com as diferentes pesquisas citadas acima e outras citadas por Almeida em seus artigos (2004 e 2005) podemos inferir que os museus, de maneira geral, continuam inacessíveis para grande parte da população, sendo que os de arte são os mais distantes. Também é possível notar pelas pesquisas do Smithsonian Instituition e pela própria pesquisa de Almeida que os museus de ciência costumam ser mais atrativos para os que buscam uma atividade de lazer junto a seus filhos. O fato de o Museu Paulista mostrar-se mais receptivo a outras camadas sociais que os demais pode ser explicado pela significação do mesmo no contexto da cidade e estado, como marco histórico e identitário, o que se reflete em sua popularidade, de qualquer forma este caso parece ultrapassar a questão da simples tipologia.

Esse apanhado de pesquisas, realizadas em São Paulo já no século XXI, nos mostram que muito do que fora constatado por Bourdieu e Darbel (2007) nos museus de arte da Europa nos anos 1960 ainda é realidade na São Paulo dos dias de hoje. Lembremos que a maior parte dos visitantes dos museus de arte entrevistados por Bourdieu e sua equipe também tinha alto grau de escolaridade e posicionavam-se nas camadas mais altas da hierarquia social.

Ao pensar sobre o acesso aos museus de arte, Bourdieu invoca a questão do capital artístico e das necessidades culturais:

A estatística revela que o acesso às obras culturais é privilégio da classe culta; no entanto, tal privilégio exibe a aparência da legitimidade. Com efeito, neste aspecto, são excluídos apenas aqueles que se excluem. Considerando que nada é mais acessível do que os museus e que os obstáculos econômicos - cuja ação é evidente em outras áreas - têm, aqui, pouca importância, parece que há motivos para invocar a desigualdade natural das "necessidades culturais". (BOURDIEU, 2007, p. 69)

Para Bourdieu, a influência da escola é decisiva, mas indireta. Ele relaciona a prática frequente de visitação à maior permanência do indivíduo na educação formal, mas percebe 
que uma parcela pequena dos visitantes franceses descobriu o museu através da escola. ${ }^{6}$ Para Bourdieu, a familiaridade com a obra de arte não pode operar senão por uma lenta familiarização, "mesmo que a instituição escolar reserve apenas um espaço restrito para o ensino propriamente artístico (...) ela tende, por um lado, a inspirar certa familiaridade constitutiva do sentimento de pertencer ao mundo culto" (BOURDIEU e DARBEL, 2007, p. 100)

Se juntarmos a essas considerações o fato de a pesquisa de Bourdieu ter revelado também que "A parcela dos visitantes que afirmam ter vindo a um museu pela primeira vez com a família cresce fortemente à medida que se sobe na hierarquia social" (p. 106); podemos retornar à questão ${ }^{7}$ das visitas em museus em grupos familiares e à significação dessas visitas para a relação entre a criança e o museu. Além da maior permanência na escola, o fato de as classes superiores terem a visita ao museu como prática familiar e de que esse hábito costuma ser cultivado e renovado nessas famílias a cada geração, torna compreensível que os dois âmbitos (família e escola) se reforcem no sentido de proporcionar uma familiarização e apropriação do bem cultural pelo indivíduo.

Assim, considerando Bourdieu, temos que quanto mais elevado o grau na hierarquia social, maior o estímulo e as ferramentas para que a criança se insira em ambientes como os museus. Por outro lado, quanto menor o grau ocupado na hierarquia social, menor a chance dessa iniciação ocorrer através do ambiente familiar, o que, por si só, já desprovê a experiência de uma qualidade muito íntima e específica. Embora a escola só consiga oferecer determinada face da relação com o museu, percebe-se ainda que para muitas crianças a escola é a única via que as levará ao museu.

Bourdieu (2007) defende que aumentar o tempo médio em que o cidadão permanece na escola é o meio mais eficaz para fazer crescer a visitação a museus, teatros, concertos, etc. (p. 159). Se pensarmos que a educação formal proporciona, durante o tempo em que se realiza e às vezes depois, uma familiaridade com a cultura e com a ciência tidas como oficiais, concordamos que este pode ser um caminho para aproximar a população dos bens culturais. Mas será que essa relação, estabelecida apenas a partir da escola, será suficiente? Como poderiam os museus estimular uma visitação espontânea?

\footnotetext{
6 "A influência direta da escola é bastante reduzida: 7\% somente dos visitantes franceses afirmam ter descoberto o museu pela Escola e aqueles que devem seu interesse pela pintura à influência direta de um professor são relativamente pouco numerosos." (BOURDIEU e Darbel, 2007, p. 98)

${ }^{7}$ As crianças participantes da pesquisa apontaram principalmente os pais como intermediadores de sua relação com o museu. Na dissertação faço uma reflexão sobre a significação da visita junto a familiares ao museu como fator de aproximação informal e mais prazerosa com o espaço museológico.
} 
Como o grupo familiar tem se mostrado parcela significativa da visitação espontânea dos museus, investir em atividades para esse público já tem sido visto por diversos museus como um diferenciado nicho de atuação. Agregar aos museus atividades que vão além das exposições como cursos, oficinas, cinema, música também são ações que trabalham nessa direção já que, ao diversificar as ações o museu atrai um público mais diversificado.

\section{Reflexões sobre o acesso - o tempo livre e os hábitos de lazer}

"Às vezes pode ser ladrão, às vezes pode ser bandido, às vezes pode ser outras coisas... Então por isso que eu acho que não pode todo mundo entrar no museu." (criança 5)

As crianças também apontaram o museu como programa familiar. Para continuar pensando na relação dessas crianças e suas famílias com os museus é interessante levar em conta os hábitos culturais que essas famílias possuem. O que fazem no seu tempo livre?

De Isaura Botelho trago as pesquisas, realizadas nos primeiros anos do século XXI, sobre distribuição dos equipamentos culturais em São Paulo (BOTELHO, 2003) e sobre os hábitos culturais da população da região metropolitana de São Paulo (BOTELHO e FIORE, 2004).

$\mathrm{Na}$ primeira Botelho nos mostra, por meio de mapas do município, a distribuição dos equipamentos culturais nas diferentes regiões. Observamos primeiramente que, enquanto a maioria da população entre 0 e 19 anos reside num cinturão em toda a periferia, os equipamentos culturais estão concentrados nas regiões central e oeste que são também as regiões onde os chefes de família tem maior renda mensal.

Considerando que as crianças que participaram dessa pesquisa estudam em escolas (com exceção de uma das escolas privadas) distantes das regiões periféricas, sendo, a maioria, da região centro-sul, podemos perceber que, do ponto de vista geográfico ao menos, a acesso dessas crianças aos equipamentos culturais é maior que daquelas que residem nas regiões periféricas. Isso ajuda (embora não seja o único fator) a explicar o alto grau de conhecimento que essas crianças têm dos museus e seu acesso a eles através das famílias.

Provavelmente, se esta pesquisa fosse realizada em escolas da periferia, em especial as da rede pública, o percentual de crianças a conhecer o museu e a visitá-los com suas famílias seria diferente. Essa previsão tem como base também o fato de $44 \%$ da população da região metropolitana nunca ter ido a um museu (BOTELHO e FIORE, 2004), percentual 
consideravelmente maior que o encontrado com nossas crianças ${ }^{8}$. O fato de a população que frequenta museus ser predominantemente jovem também colabora para o fato de um maior percentual entre as crianças, além do local de residência.

Embora eu pretenda alertar, através de Botelho, para a desequilibrada distribuição de equipamentos de cultura e lazer em nossa cidade, concordo com a autora quanto ao fato de que este é apenas um dos muitos fatores a serem considerados quando se pensa em ampliar o acesso aos bens culturais.

Os hábitos culturais cultivados pelas famílias e seus membros deve ser considerado assim como o conceito que se tem de democratização cultural. A pesquisa de Botelho e Fiore (2004) que investigou o uso do tempo livre e as práticas culturais na região metropolitana de São Paulo nos permite conhecer melhor o contexto cultural na cidade. A pesquisa, realizada com cerca de duas mil pessoas, sai da esfera da cultura erudita e busca falar de entretenimento, cultura e lazer de uma maneira geral. Posteriormente uma pesquisa de aprofundamento foi realizada com cinco por cento do total de participantes.

O que podemos destacar dos resultados obtidos é a grande participação das atividades domiciliares de lazer, especialmente aquelas ligadas aos equipamentos eletrônicos como TV, rádio e computador; a predominância de uma concentração maior de atividades no público mais jovem, escolarizado e rico; e a importância da escolaridade dos pais.

Para efeito de tabulação, as atividades foram divididas entre atividades domiciliares ou externas. As atividades domiciliares foram predominantes, o que, segundo a autora, confirma uma tendência internacional chamada como "cultura de apartamento" ou "cultura em domicílio". Este tipo de atividade despende menos tempo e dinheiro e torna-se cada vez mais comum com a popularização dos equipamentos eletrônicos, principalmente entre os mais jovens.

No entanto, ao contrário do que se poderia pensar, não há uma concorrência direta entre atividades domiciliares e externas, uma vez que, segundo a pesquisa de Botelho, as pessoas que praticam mais atividades domiciliares também são as que acumulam um maior número de práticas culturais externas, enquanto as que menos praticam uma, também são menos praticantes da outra. Podemos apontar também, embora isso não esteja na pesquisa citada, que cada vez mais as atividades domiciliares ligadas a equipamentos eletrônicos se

\footnotetext{
${ }^{8} 12 \%$ das crianças participantes da pesquisa afirmaram nunca ter ido a um museu.
} 
dão também fora do ambiente doméstico, dada a incrível portabilidade e diversidade de recursos que temos hoje com MP3s e MP4s, celulares, Ipads, e notebooks. Essa intersecção promovida pelas novas tecnologias leva a música, a fotografia e as relações virtuais que se estabeleciam a partir de casa para espaços como os museus e as bibliotecas podendo ser, inclusive, colaboradoras das atividades externas em sua difusão.

Em ambas as classes de atividades, Botelho notou maior predominância de um público jovem, escolarizado e rico. Interessante também, além dos dados que a autora traz, é a reflexão sobre as pessoas distantes do mercado profissional e sua relação com as práticas culturais externas como uma extensão da própria participação do entorno social:

Não estar vinculado a uma atividade profissional, os dados apontaram, torna-se grande desestímulo a ser um ativo praticante fora de casa: aqui não se considera apenas o desemprego, mas a aposentadoria e as atividades domésticas. Nesse caso, a questão financeira assume um peso importante. Também o isolamento, o baixo nível de informação - propiciado pela falta de convívio com a própria cidade - podem ser considerados como fatores. (BOTELHO, 2004, p.6)

Acredito que possamos incluir as crianças e os jovens estudantes como "vinculados a uma atividade profissional" no sentido em que a sua participação na escola/universidade os insere, obrigatoriamente, no circuito urbano propiciando contato com pares e não pares, acesso a informações e contato com as diversas questões que envolvem essas comunidades.

O apontado por Botelho sobre as pessoas distantes das atividades profissionais reforça o fato de que os mais jovens, escolarizados e ricos tem maior acesso às práticas culturais, especialmente as externas; e também de quanto este acesso pode refletir uma parte da relação do indivíduo com a própria cidade, seus espaços, problemas e assuntos. Por este prisma, temos o museu não como o único, mas como um dos espaços possíveis para a prática da cidadania e pertencimento que pode ser apresentado às crianças.

Dando continuidade a este raciocínio podemos invocar o fato, também constatado por Botelho e já observado em pesquisas realizadas em outros países, da grande relevância da escolaridade dos pais para a ampliação e diversificação das práticas culturais dos filhos:

O fato de alguém ter ambos os pais com baixo nível de escolaridade aumenta em $395 \%$ a sua chance de ser um não praticante da cultura do 
sair. O fato de apenas um dos pais ter o nível médio de escolaridade já aumenta a possibilidade do indivíduo ser um grande praticante. A bagagem cultural herdada dos pais é identificada como um preditor decisivo na vida de um adepto da "cultura do sair": ter pais altamente escolarizados é mais importante do que o nível de renda e de diploma do próprio indivíduo. Ou seja, sabe-se que o acesso a cultura resulta fortemente das transmissões familiares: filhos de pais com nível alto de escolaridade têm o acesso a cultura tradicional facilitado. (BOTELHO, 2004, p. 16)

Mantecón completa, a esse respeito:

Os públicos se constituem a longo prazo na vida cotidiana familiar, em grupo e na formação escolar. A família, as comunidades de pertencimento e a escola contribuem com este processo através da transmissão do capital cultural necessário para identificar e desfrutar as ofertas culturais. Trata-se de um conjunto de disposições incorporadas que permitem distinguir, avaliar e usufruir as práticas e ofertas culturais. São elas que produzem a certeza de se sentir convidado. (MANTECÓN, 2009, p. 188)

O comentário de Mantecón e os dados apresentados por Botelho nos levam de volta à importância das experiências familiares na relação entre a criança e o museu. Pais com maior escolaridade vão e levam com mais frequência seus filhos ao museu, ao mesmo tempo, ir a museus com os pais fortalece tanto o vínculo familiar quanto o vínculo com o espaço museológico em si. Através de contextos sociais como a família e a escola a criança é apresentada aos espaços públicos da cidade e, a partir das práticas que se estabelecem em um e outro âmbito, é desenvolvida uma relação que pode envolver aspectos como familiaridade, reverência, curiosidade, distanciamento, apropriação, etc., aspectos esses que podem vir a delinear a característica da relação entre este indivíduo e o espaço em questão.

Sobre a escolaridade dos pais, fator comumente associado à renda, podemos considerar o fato de que, entre as crianças que participaram da pesquisa, a maior ocorrência de crianças que visita museus de maneira mais frequente está localizada nas duas escolas particulares, embora em uma delas os alunos nunca tivessem visitado a um museu com a escola. ${ }^{9}$

\section{Reflexões sobre o acesso - democratização ou democracia}

\footnotetext{
${ }^{9}$ Nesta escola encontramos vários alunos que nunca visitaram um museu, no entanto, entre os que já visitaram, todos afirmaram terem ido mais de uma vez.
} 
"Todo mundo pode ir porque é um lugar público e não tem diferença de pessoa. Todo mundo é igual." (criança 6)

Ademais desses e outros fatos trazidos por sua pesquisa, Botelho trata a questão do acesso e da democratização da cultura com cuidado. A autora questiona a ideia de Cultura com letra maiúscula e as propostas provenientes das décadas de 1960 e 1970 de uma democratização onde apenas a cultura erudita é levada em consideração. Segundo a autora,

Tais políticas repousam sobre dois postulados: o primeiro define que a cultura erudita é aquela que deve ser difundida; o segundo supõe que basta haver o encontro (mágico) entre a obra e o público (indiferenciado) para que este seja por ela conquistado. (BOTELHO e FIORE, 2004, p. 3)

Ela lembra que políticas que se baseiam nessas concepções normalmente se preocupam apenas com as questões materiais, como a má distribuição dos equipamentos e a gratuidade de ingressos. É nesse sentido que a pesquisa realizada pela autora engloba tanto as formas eruditas quanto as populares, tanto as externas e tradicionais quanto às domiciliares e tecnológicas, tanto as práticas culturais quanto as práticas de lazer em geral.

Como Botelho, acredito numa concepção mais ampla de cultura, e também de museu. Nem só os museus tradicionais devem ser levados em conta, da mesma forma nem só os novos merecem nossa atenção, por serem novos. A convivência entre as diversas formas de museus e de práticas culturais lado a lado enriquece e amplia as possibilidades de identificação e apropriação, assim amplia a possibilidade de difusão e consumo cultural enquanto processo de cidadania, já que, como nos apresentou Botelho, o consumo de uma determinada prática cultural estimula em vez de concorrer com o consumo de outras e diferentes práticas.

Hoje parece claro que investir na democratização cultural não é induzir a totalidade da população a fazer determinadas coisas, mas sim oferecer a todos a possibilidade de escolher entre gostar ou não gostar de algumas delas, colocando os meios à disposição, (BOTELHO e FIORE, 2004, p. 3-4)

Para mim, a palavra chave do excerto acima é "escolher", e escolher só é possível quando existe e se percebe a possibilidade. Não acredito que todos devam optar por utilizar seu tempo livre nas mesmas atividades, não creio que, ao final, se o acesso realmente fosse 
universal, todos escolheriam estar no museu. Porém, essa escolha de "não estar" só é legítima se é percebida a possibilidade de "estar". Se as pessoas, como algumas das que responderam à pesquisa da Pinacoteca (2007) não conhecem o museu e não compreendem que podem ser bem-vindas lá dentro, então, a opção de não frequentá-lo não é uma opção, é apenas um efeito. Para escolher, portanto, o indivíduo precisa conhecer e perceber como possível.

Quando uma criança nos alerta que não podia entrar no museu "porque não conhecia nada"; quando outras nos lembram que alguns perfis podem não ser aceitos no museu; quando chamam a atenção para a questão socioeconômica; ou dizem que no museu não existem coisas para as crianças pequenas estão nos mostrando pontos onde a escolha não é legítima, pois a possibilidade (ou a crença nela) não é plena.

Nessa linha ainda, Botelho defende o que chama de "democracia cultural" a partir do pensamento da cultura mais ampla e diversificada, "diferente da democratização unidirecional até agora orientadora de políticas" pautada na cultura erudita e já consagrada. Sobre o problema de uma concepção restrita e hegemônica da cultura para a qual se busca, desde Bourdieu, acesso irrestrito, Bernard Darras (2008) propõe o que chama de "ecologia das culturas". Essa seria uma terceira opção que iria além das já consideradas, manter a cultura das elites para as elites ou democratizar a todo o custo essa mesma cultura das elites, como bem em si.

A cultura democrática ou ecologia das culturas é uma proposta que trata de "relativizar a exclusividade do patrimônio elitista, tornando-o inclusive mais inteligível, reintegrando-o à cultura visual do seu tempo"10. (DARRAS, 2008, p. 142) Ou seja: colocando-o lado a lado com outros objetos da cultura visual da mesma época, não considerados, até então, para estar ao lado das obras primas. Dessa forma, Darras concebe uma maneira pela qual as formas de cultura já consagradas não continuariam a ser consideradas como as únicas legítimas, mas também não seriam descartadas como algo fora de seu tempo e distante da população. A ecologia das culturas permite a legitimação das demais formas de cultura, ao mesmo tempo em que contribui para a aproximação do público em geral com objetos e obras que hoje são conceitualmente distantes e, muitas vezes indecifráveis.

\section{Reflexões sobre o acesso: identidade e pertencimento}

\footnotetext{
${ }^{10}$ Tradução nossa
} 
"Museu é legal porque ele mostra coisas interessantes e que a gente nunca tinha visto." (criança 7)

As formas de concepção da cultura sugeridas por Botelho e Darras, se incorporadas ao diaa-dia dos museus e suas exposições, poderiam contribuir para uma maior aproximação entre este e seu público, especialmente nos casos dos museus de arte, ao passo que caminham em direção a possibilidade do público reconhecer-se no museu, ou seja, do surgir de um sentimento de pertencimento entre cidadão e bem cultural.

Mas se barreiras materiais e sócio-culturais se opõem ao acesso da população à maioria dos museus, quais são os fatores que a leva até eles? O que motiva uma pessoa a despender parte de seu tempo livre em uma dessas instituições?

John Falk (2009) nos fala bastante de motivação ao estudar experiências de visitantes em museus nos Estados Unidos. Mais especificamente, relaciona as motivações de visita às necessidades relacionadas à identidade.

Anteriormente, Falk e Dierking já haviam estudado a experiência vivida no museu e chegado ao que chamam de Modelo de Experiência Interativa, publicado em seu livro The museum experience (1992). Esse modelo descreve a experiência do visitante no museu a partir da intersecção de três contextos fundamentais: pessoal, social e físico e serviu de referência a outros trabalhos sobre o assunto, inclusive no Brasil, como os de Grinspum (2000) e Almeida (2005).

Afirmando, no início desse novo trabalho, que "os visitantes são o centro da existência dos museus do século XXI" e que "os museus de hoje não tem outra escolha a não ser pensar seriamente sobre quem são os seus visitantes e por que eles vêm ao museu" (FALK, 2009, p. 20, tradução nossa); o autor retoma algumas questões de seus estudos anteriores para lembrar-nos que o conteúdo do museu não é tudo, quando se pensa em motivação de visita e que características demográficas como sexo e idade não são suficientes para compreender essas motivações.

Retoma o modelo desenvolvido com Dierking ao apontar a experiência no museu como composta de diferentes contextos que se misturam durante as visitas. Se o contexto pessoal é responsável pelos conhecimentos e experiências prévias dos visitantes, suas expectativas, necessidades e crenças; o contexto social é aquele que percebe a experiência no museu como uma atividade de interação social, tanto com as pessoas pertencentes ao mesmo grupo do visitante (família, amigos, grupo, guias) quanto com os outros visitantes e 
funcionários do museu. O contexto físico, por fim, refere-se à relação do visitante com o espaço do museu, suas características arquitetônicas, sua comunicação visual, orientação, ruídos, temperatura, etc.

A partir de então, o autor sugere que paremos de pensar em conteúdo e visitante como fatores fixos e imutáveis designados a atingir resultados específicos ou limitados por características demográficas fechadas.

O resultado deste novo pensamento é um modelo de experiência de visitantes de museu formado em torno do que chamo de ' motivações de visita associadas à identidade do visitante' - série de razões específicas que os visitantes usam para justificar tão bem como organizar sua visita, e em última instância usam a fim de dar sentido a suas experiências em museus (...). Nesta nova tipologia nem os visitantes nem os museus e suas exposições são imutáveis e fixos; cada um é fluido e muda - o mesmo indivíduo pode se engajar na visita da mesma exposição e conteúdo por caminhos fundamentalmente diferentes dependendo das suas atuais motivações de visita relacionadas à identidade. (FALK, 2009, p. 35-36) ${ }^{11}$

Mas quais seriam essas motivações, e como é possível mensurá-las e estudá-las? A cada capítulo da publicação, o autor passa pelos diversos fatores que envolvem a visita: o museu, o visitante, a própria visita, a satisfação e as memórias, trazendo referências de outras pesquisas na área e, a cada etapa, um trecho de uma entrevista realizada com um visitante de museu no dia ou até meses após a visita. Aos poucos essas entrevistas vão se configurando como exemplos das diferentes motivações que levam, segundo o autor, as pessoas aos museus. Mais que isso, o autor consegue, a partir das entrevistas, refletir sobre como as pessoas dão sentido às suas experiências nos museus, o que é importante e memorável e como essas experiências reforçam ou refazem a própria concepção que o visitante possuía sobre a instituição.

Como mencionei, para Falk as visitas a museus são fortemente motivadas por necessidades vinculadas à identidade. O visitante, então, a partir de seu conhecimento e experiências prévias (no museu ou através de outros), percebe o museu como capaz de satisfazer, em maior ou menor grau, essas necessidades. De

\footnotetext{
${ }^{11}$ Tradução nossa.
} 
acordo com as suas pesquisas entrevistando visitantes de museus, os museus são espaços que permitem aos visitantes desempenhar um ou mais dos papéis abaixo:

1) Explorador (explorer);

2) Facilitador (facilitator);

3) Candidato a experiência (experience seeker);

4) Profissional/Amador (professional/hobbyist);

5) Recarregador (recharger).

Explorador é aquele visitante que explora o museu à procura de coisas que thes pareçam interessantes ou satisfaçam sua curiosidade, são pessoas que vivenciam o museu como espaço de descoberta e valorizam a aprendizagem. Facilitador é aquele que assume o papel de facilitar a experiência no museu a outro, como pais com seus filhos por exemplo, o foco é a satisfação do outro e não de si mesmo. Candidato à experiência é o visitante que procura cumprir uma determinada agenda de locais e/ou objetos que "devem ser vistos" por sua significação em determinada localidade, exemplificando podemos dizer que é o visitante que procura a Monalisa do Louvre ou o Pedro Américo do nosso Museu Paulista.

Profissional/Amador é aquele visitante que, devido à profissão ou como forma de passatempo, tem um conhecimento acima da média sobre o museu e seu conteúdo e o procura com objetivos específicos. O recarregador é aquele que busca no museu uma experiência de restauração, algo que o desvincule por um momento das pressões da vida cotidiana. Falk comenta ainda que nenhuma dessas categorias é totalmente pura. As motivações para visita misturam frequentemente mais de uma categoria. Cada dia pode predominar uma delas para cada visitante.

Meus dados sugerem e as minhas pesquisas posteriores apenas confirmam esta observação inicial, que cada uma destas cinco grandes categorias representa um ponto de vista separado, fundamental, de muitos visitantes sobre quais necessidades os museus podem suprir em um dia particular. $(\ldots)$

Eu acredito que o meu quadro é baseado em uma combinação de teoria e dados que acuradamente representam as percepções relacionadas à identidade profundamente enraizadas e as crenças do público para porque é valioso visitar o museu. Consequentemente estas categorias refletem as razões que as pessoas têm para visitar museus, e também refletem 
atributos básicos de lazer que o público percebe que os museus podem proporcionar. (FALK, 2009, p. 64-65) ${ }^{12}$

Ver coisas interessantes/diferentes, ser desafiado, estar com outras pessoas e relaxar são alguns dos atributos de lazer que satisfazem tanto as motivações elencadas por Falk (2009) quanto aos atributos de lazer já encontrados por Hood (2004) $)^{13}$ e ainda podem ser vistos, em parte, nas falas de nossas crianças. A forte ligação entre museu e aprendizagem citada pelas crianças como motivo para visitar essas instituições também não foi esquecida por Falk que acredita que a motivação da aprendizagem permeia todas as outras categorias.

Falk cita a pesquisa de James Bigley, Daniel Fesenmaier, Mark Lane e Wesley Roehl, realizada no final dos anos 1980 a respeito das motivações de filiação e doações financeiras dos indivíduos associados a vários museus de San Antonio - Texas. O que é interessante nesse estudo para Falk, e que outros não revelam, é que a aprendizagem sempre faz parte da equação. "Para Bigley a aprendizagem nunca está ausente (ao menos para os visitantes mais frequentes), embora ela se manifeste de modo mais pronunciado em alguns visitantes que em outros." E Falk completa "Alguns vem aprender explicitamente, outros vem aprender implicitamente, mas todos vem aprender!" (FALK, 2009, p. 55-56, tradução nossa)

Resumindo, no processo que vai de conhecimento prévio e motivação à visita em si há um fluxo contínuo de retroalimentação onde uma experiência se soma e reforça a outra. Esse movimento pode ser visualizado, com mais detalhes, no modelo abaixo:

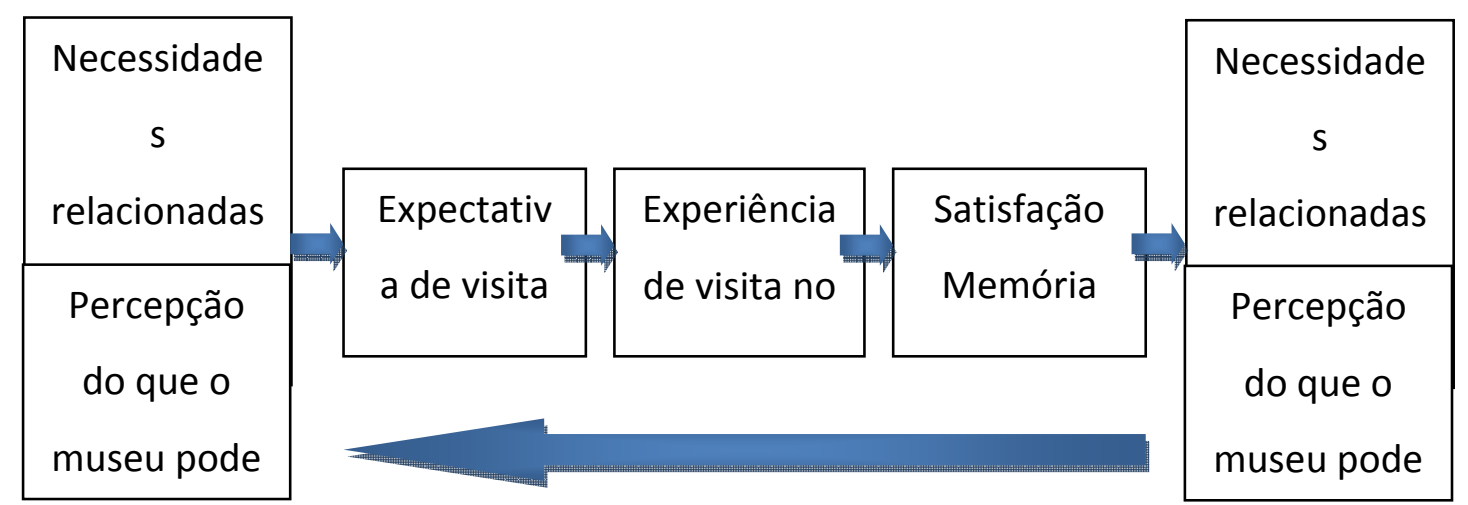

Gráfico 1: Modelo reproduzido com base no diagrama encontrado em FALK, 2009, p. 89 - (tradução nossa)

${ }^{13}$ Em seu artigo "Staying Away: Why People choose not to visit museums" Marilyn Hood fala sobre as decisões da população em relação a como passar seu tempo livre, e traz os resultados da sua pesquisa realizada na década de $1980 \mathrm{em}$ Toledo, Ohio sobre por que as pessoas fazem uso ou não os museus e outras atividades de lazer. Segundo o texto sugere, com base em uma grande revisão bibliográfica do assunto, seis critérios são utilizados pelos indivíduos para julgar suas experiências de lazer: interação social, fazer algo interessante, sentir-se confortável e à vontade, ter o desafio de novas experiências, ter a oportunidade de aprender e participar ativamente. 
A partir do modelo de Falk e suas falas podemos inferir que a experiência da visita começa muito antes de chegar ao museu, que a percepção da própria identidade como imagem a ser construída/reforçada/percebida junto às concepções que a pessoa tem de museu delineiam as expectativas para a visita. Chegado o momento da visita, quanto maior for a semelhança entre o que se espera encontrar e o que se encontra de fato, maior a chance de satisfação. A memória retida também se relaciona fortemente com o papel desempenhado pelo visitante durante a visita, ela é mais forte quando fatores como escolha, controle e emoção estão envolvidos na experiência. A experiência construída, então traduzida por satisfação e memória, irá alimentar tanto a concepção que a pessoa tinha de museu, quanto a sua própria identidade, podendo reforçar crenças e comportamentos anteriores ou provocar mudanças. Dessa mistura sairão novas motivações e expectativas para visitas futuras.

Levando em consideração o modelo retroalimentável de Falk fica evidente que, quanto mais um visitante conhece o museu e os benefícios que ele proporciona, mais provável que obtenha satisfação na visita e que esta reforce sua concepção sobre a instituição e sobre o que ele próprio procura (e pode encontrar) ali. Da mesma forma, o papel do museu nessa recepção do visitante (e especialmente do primovisitante) é fundamental já que pode reforçar ou modificar concepções pré-existentes, reforçando o vínculo ou o distanciamento entre ambos.

A partir desse modelo, podemos concluir que essas experiências vividas pelas crianças podem reforçar as maneiras como percebem a si mesmas, suas relações com os seus acompanhantes (pais, colegas, etc.) e suas concepções de museu. Assim, uma criança que chega ao museu com uma concepção de que só verá coisas antigas ${ }^{14}$, já chega com certa propensão (expectativa) de ver coisas antigas e a visita pode reforçar apenas essa ideia de museu. Por outro lado, se nessa nova experiência encontra, por exemplo, dispositivos interativos e isso Ihe chama a atenção, poderá sair da visita com a ideia de que o museu, além de coisas antigas, também pode conter coisas atuais, coisas que podem ser tocadas, etc. A cada nova visita ao museu a criança vai somando as realidades encontradas àquelas que já conhecia, reforçando ou modificando sua própria concepção de museu.

\footnotetext{
${ }^{14}$ Durante a pesquisa as crianças associaram com muita frequência o museu às coisas antigas e ao passado. Cabe pensar, não somente de onde vem essa concepção de museu (assunto que foi explorado na dissertação) mas como ela é reforçada continuamente.
} 
Voltando ao visitante em geral, dado que a concepção de museu também é passada àqueles que ainda não o conhecem através do boca-a-boca, as impressões que o visitante tem desse espaço podem determinar não apenas a próxima visita daquele que veio ao museu, mas também as de uma rede de pessoas com as quais ele se relaciona. Portanto, sentir-se à vontade dentro do espaço do museu, reconhecer-se, encontrar espaço para desempenhar o papel que considera importante em sua vida naquele momento (seja ele de pai, filho, profissional, turista, professor, pesquisador, cidadão, entre outros) é fundamental para que as portas dos museus permaneçam abertas aos olhos do público e para que este se sinta convidado a entrar.

\section{6._Conclusão}

O mais significativo, e a essência que se extrai da soma de todos esses autores e pesuisas que falaram sobre público de museu, sobre acesso e não acesso é a relação que estabelecem com a identidade, com o reconhecer-se, enfim, com o pertencimento. Se quando éramos pequenos não podíamos ver, porque não conhecíamos nada, é porque não nos reconhecíamos no museu. Mas se as crianças ainda apontam que os pequenos não devem ir aos museus, somos levados a pensar que talvez seja o próprio museu que ainda não os percebe totalmente como público, que ainda não conseguiu abrir espaço suficiente para seu pertencimento.

Criança 1 - É assim, o museu, assim, quando você quando era criança não podia ver

Paula - Por que quando era criança não podia ver? Criança 1 - Porque a gente ainda não conhecia nada

Paula - Não conhecia nada?

Criança 1 - Não

Paula - E isso faz tempo?

Criança 1 - Faz

Paula - E agora você já pode? balança a cabeça afirmativamente

\section{REFERÊNCIAS BIBLIOGRÁFICAS}

ALMEIDA, Adriana Mortara. Os visitantes do Museu Paulista: um estudo comparativo com os visitantes da Pinacoteca do Estado e do Museu de Zoologia. In: Anais do Museu Paulista. São Paulo, v.12. jan./dez. 2004. p. 269-306. 
ALMEIDA, Adriana Mortara. O Contexto do visitante na experiência museal: semelhanças e diferenças entre museus de ciência e de arte. In: História, Ciências, Saúde - Manguinhos, v.12 (suplemento), 2005. p. 31-53.

BOTELHO, Isaura. Os Equipamentos Culturais na Cidade de São Paulo: um desafio para a gestão pública. In: Espaços e Debates. São Paulo: USP/NERU, 2003.

BOTELHO, Isaura e FIORE, Maurício. O uso do tempo livre e as práticas culturais na região metropolitana de São Paulo. Trabalho apresentado em VIII Congresso Luso-AfroBrasileiro de Ciências Sociais. Coimbra: 16, 17 e 18 de set de 2004.

BOURDIEU, Pierre; DARBEL, Alain. O Amor pela Arte: Os museus de arte na Europa e seu público. 2. ed. Tradução: TEIXEIRA, Guilherme João de Freitas. São Paulo: Edusp, 2007.

DARRAS, Bernard. Del patrimonio artístico a la ecología de las culturas. In: ARRIAGA, Imanol Aguirre; FONTAL, Olaia; DARRAS, Bernard; RICKENMANN, René. El acesso al patrimonio cultural. Retos y debates. Pamplona, Espanha: Cátedra Jorge Oteiza; Universidade Pública de Navarra, 2008. p. 119-165

FALK, Jonh H. e DIERKING, Lynn D. The museum experience. Washington: Wlhalesback Books, 1992

FALK, John $\mathrm{H}$. Identity and the museum visitor experience. Walnut Creek: Left Coast Press, Inc., 2009

GRINSPUM, Denise. Educação para o Patrimônio: Museu de Arte e Escola Responsabilidade compartilhada na Formação de Público. Tese de Doutorado - FE - USP. São Paulo, 2000.

HOOD, Marilyn G. Staying Away: Why People choose not to visit museums (1983). In: Reinventing the museum: Historical and Contemporary Perspectives on the Paradigm Shift. Edited by Gail Anderson, Altamyra Press, Calif. c.2004 p. 150-157.

MANTECON, Ana Rosas. O que é público? In: Revista Poiesis n.14, Dez 2009. p. 175-215. Disponível em:<http://www.poiesis.uff.br/> Acesso em 13 jun. 2011 
OBSERVATÓRIO de museus e centros culturais. Pesquisa Perfil - Opinião 2006/2007: Análise descritiva preliminar dos dados agregados dos museus participantes da pesquisa em São Paulo. Junho, 2008

PINACOTECA - Área de Ação Educativa. Você e o museu: Pesquisa de perfil do público da Pinacoteca do Estado. São Paulo: Pinacoteca, 2002.

PINACOTECA - Núcleo de Ação Educativa. Expectativas e percepções em relação à Pinacoteca 2007: Pesquisa de público de entorno. São Paulo: Pinacoteca, 2007.

PINACOTECA e ALMEIDA, Adriana Mortara. Avaliação da Exposição de Longa Duração da Pinacoteca do Estado. São Paulo: Pinacoteca, 2008

SELLI, Paula Hilst. Crianças, museus e formação de público em São Paulo. Dissertação de Mestrado apresentada ao Instituto de Artes da Universidade Estadual Paulista (UNESP). São Paulo, 2011. 